\title{
Chapter 2 \\ Macrosocial Determinants of Population Health in the Context of Globalization
}

\author{
Lia S. Florey, Sandro Galea, and Mark L. Wilson
}

\section{Introduction}

We live in an increasingly interconnected world, as some like to say, a "global village." As in any village, social, economic and biophysical environments shape individual action and interaction, which, in turn, influence the quality of life and the health of inhabitants. Technology, information, media, food, goods and services, as well as environmental pollution and diseases are shared among villages, cities, countries and continents. Not only are these exchanges great in scope, but the magnitude and speed of interaction among individuals and populations is also increasing. For example, international trade grew $8.6 \%$ per year during the decade 1990-1999 (World Trade Organization, 2000a, b), with an estimated US\$1.7 trillion in daily global trading (Lee, 2000). An estimated 760 million people traveled to international destinations in 2004 (World Trade Organization, 2005), and circumnavigation of the globe is now possible in a mere 36 hours (Smolinski, Hamburg, \& Lederberg, 2003). Immigration contributes to global exchanges, with an estimated 175 million individuals spending at least one year in another country (United Nations, 2002). Additionally, approximately 17 million refugees and internally displaced persons migrate from their homes every year (United Nations High Commissioner for Refugees, 2004). These trends of growing interactions on the global scale shape the environments in which we live and which influence our well-being and our health.

The term globalization is used to denote these global trends in exchanges and interactions. Historically, globalization has been defined in economic terms as "the removal of tariff and non-tariff barriers to trade" (Weisbrot, Baker, Kraev, \& Chen, 2002) or "the process whereby national and international policy-makers promote domestic deregulation and external liberalization" (Cornia, 2001). We argue, as have many before us, that globalization is comprised of much more than fiscal trends and policies. For the purposes of this review we use an expansive definition for which globalization consists of the "processes contributing to intensified human interaction in a wide range of spheres (that is, economic, political, social, environmental) and across three types of boundaries-spatial, temporal and cognitive- that have hitherto separated individuals and societies" 
(Bettcher \& Lee, 2002). Implicit in this definition is the ubiquity of globalization processes and the pervasiveness with which these processes affect human lives.

Although the existence of global influences on individuals and populations is clear, the effect of globalization on individual well-being and population health is not well established. Empirical evidence suggests both positive and negative effects of globalization on health, but there is no simple equation that can encapsulate how globalization may improve, or harm, population health. Instead it is likely that myriad processes comprise globalization, and each may influence the health of populations through multiple pathways. The challenge lies in elucidating the mechanisms by which globalization affects health. An understanding of these mechanisms will inform the decision-making process and enable implementation of policies that will mitigate the negative consequences of globalization and enhance its potential positive influences.

This chapter addresses an important gap in knowledge on the global context of population health by providing a conceptual framework from an epidemiologic perspective. The aim of this framework is to facilitate understanding of the complex relationships among globalization, macro-level determinants of health, and population health. The relationships between each component of the framework and population health will be briefly discussed followed by a presentation of potential mechanisms that may explain these associations. This chapter integrates current knowledge pertaining to the relationships of interest, generates hypotheses about mechanisms where current knowledge is scarce, and presents a brief discussion of methodological issues pertaining to epidemiologic studies of globalization and population health. We acknowledge that we approach this chapter as epidemiologists, building explicitly on epidemiologic multilevel thinking. We suspect that other disciplinary perspectives may approach the issue of globalization differently. We hope that our approach is illuminating, regardless of the reader's disciplinary orientation, and may engender discussion and debate that can bring about cross-disciplinary synthesis.

\subsection{Framework}

Globalization is characterized by a plethora of components that may influence health at the population level. We propose a framework that summarizes a few key characteristics of the global, national and community level environments that are associated with population health. This framework builds on previously published conceptual models (Huynen, Martens, \& Hilderink, 2005; Labonte et al., 2002; Spiegel, Labonte, \& Ostry, 2004; Woodward, Drager, Beaglehole, \& Lipson, 2001) and on the broader literature examining the effects of contextual determinants on health (Galea, Freudenberg, \& Vlahov, 2005; Galea, Rudenstine, \& Vlahov, 2005; Kaplan, 1999; Link \& Phelan, 1995).

Our framework (Figure 2.1) builds upon the emerging thinking about multiple "levels" of determination of population health (Kaplan, 1999) and suggests that three levels of variables may be considered central to the role played by globalization in population health. Global-level factors (including global trade, income distribution, population movement, global governance and communications) are 


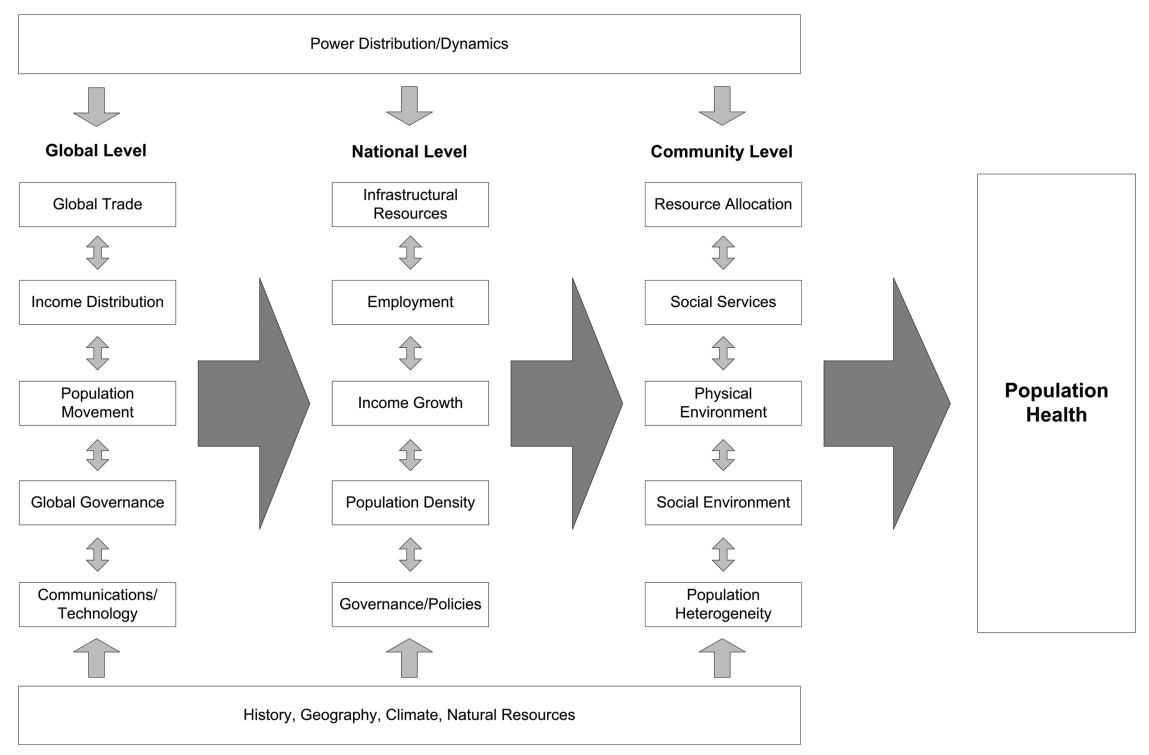

FIGURE 2.1. Conceptual framework summarizing how characteristics of the global, national and community-level environments may influence population health

conceptualized to shape national-level factors (infrastructural resources, employment, income growth, population density, and national governance). The national-level factors influence community-level factors (resource allocations, social services, physical environmental, social environment, and population heterogeneity). In turn, each of these elements are affected by global distributions and dynamics of power, as well as by underlying conditions such as history, climate, and geography that are represented by the horizontal rows at the top and the bottom of the model. Although this framework is designed to be hierarchical, with global-level factors influencing population health through the national and community-level factors, we recognize that there will be some direct effects between elements at any level of organization and health. Similarly, we consider that these associations could be bidirectional (a national-level factor may directly influence a global-level factor) as well as vertical (interrelationships among several components at the global level). The aim of this conceptual model, however, is to present the integral role of global-level processes in influencing population health as part of a multivariate, multilevel framework. This simplification of what is undoubtedly a far more complex web of associations is intended to clarify the current state of knowledge and help guide future research.

Although an unconventional approach, we begin by exploring the proximal relationships between community level factors and population health before approaching the more distal national-level and global-level factors (moving from right to left in Figure 2.1). This strategy allows clearer and more explicit development of the pathways through which globalization exerts influence on health and is compatible with clinical and epidemiologic approaches to health research. 


\section{Community-Level Processes}

Despite extensive public health research focusing on the "community," a definition of this concept remains elusive. Considerable recent investigations have addressed "neighborhoods," while others have grouped people into census tracts or other administrative units. Such groupings may be convenient, affordable or otherwise useful for spatial analyses; however, they do not always carry social meaning for individuals. For purposes of this review, communities are defined as any sub-national aggregation that is socially meaningful to local residents.

As many scholars have noted, diverse aspects of community life that we characterized in Figure 2.1 play an enormous role in forming the health profiles of populations. These are the most proximal of the macro-level health determinants that are addressed in this chapter and should therefore affect population health indicators through the most direct pathways. Yet we recognize that multiple elements of communities may interact to shape health indicators through more complex, indirect pathways. The brief descriptions and examples presented below are not meant to be exhaustive, but rather to illustrate a few specific mechanisms whereby population health is affected by the environmental, social and political realities of communities.

\subsection{Resource Allocation}

Community allocation of resources affects population health through direct and indirect pathways. Directly, certain basic resources are necessary for the maintenance of body functions. Access to a sufficient quantity and quality of food is essential for proper nutrition. Malnutrition and undernutrition have severe consequences for growth and development of children (de Onis, Monteiro, Akre, \& Glugston, 1993; Stevenson, Latham, \& Ottesen, 2000; Weinreb et al., 2002), as well as for the functioning of the immune system and prevention of disease (Cunningham-Rundles, McNeeley, \& Moon, 2005). Adequate nutrition requires either enough arable land for local food production or access to markets with imported food and income with which to purchase the food. Not only are the absolute quantities and costs of these resources in a community important, but the distribution of these resources also contributes to shaping health outcomes. For example, the availability and cost of fresh fruits and vegetables and the spatial patterns of supermarkets are strongly linked to the income and racial characteristics of neighborhoods in Detroit (Zenk et al., 2005; Zenk et al., 2006)

Similarly, the quantity and quality of a community's water supply is an important determinant of people's health (United Nations, 2005). Insufficient water sources may lead to insufficient food supplies due to lack of irrigation of crops. The economies of developing countries are highly dependent on agriculture, which generates $80 \%$ of export earnings; however, this important source of income requires almost $70 \%$ of the world's freshwater use (United Nations, 2005). In communities where potable water sources are far from residences, considerable time and energy is expended supplying households with water (Cosgrove \& Rijsberman, 1998). 
It has been estimated that 40 billion working hours are lost in Africa each year due to time spent transporting water, with the burden falling most heavily on women and children (United Nations, 2005). Poor quality water in conjunction with poor sanitation and hygiene is responsible for 1.6 million deaths per year due to diseases such as cholera, typhoid fever, trachoma, and schistosomiasis, to name a few (World Health Organization, 2004). Water can also be a source of toxicity. The well water consumed by 28-35 million Bangladeshi (United Nations, 2005) contains high levels of arsenic, causing skin lesions and various cancers (Smith, Lingas, \& Rahman, 2000).

Shelter from the elements is another essential resource influenced by communitylevel factors. Good quality construction (Konradsen et al., 2003; Yé et al., 2006), and screened windows and doors (Lindsay, Emerson, \& Charlwood, 2002) prevent spread of vector-born diseases such as malaria. Quality housing protects inhabitants from climate extremes (heat, cold, wet), which contribute to disease and mortality (Evans, Hyndman, Stewart-Brown, Smith, \& Petersen, 2000; Gemmell, 2001; The Eurowinter Group, 1997). Insufficient physical space in a community may lead to overcrowded housing, which facilitates the spread of communicable diseases such as tuberculosis (Antunes \& Waldman, 2001) and helminth infections (Carneiro, Cifuentes, Tellez-Rojo, \& Romieu, 2002). Indoor air quality is another important characteristic of housing that can influence the risk of respiratory diseases (Bruce, Perez-Padilla, \& Albalak, 2000).

In a similar manner, medications also are essential community resources. Insufficient or unreliable supplies of medications have serious health repercussions by contributing directly to morbidity and mortality as well as to drug resistance (Draper, Brubaker, Geser, Kilimali, \& Wernsdorfer, 1985).

Aside from essential resources, communities also have differential access to goods that may be deleterious to health, such as tobacco, alcohol and narcotics. For example, neighborhoods in Baltimore, Maryland, comprised predominantly of African Americans have a higher density of alcohol distributing outlets than neighborhoods with different racial demographics (LaVeist \& Wallace, 2000). Many other such directly detrimental social impacts exist at the community level.

Indirectly, the distribution, volatility, and cost of these resources in the community are likely to have effects on social interactions and behaviors which may shape population health (Gopalan, 2001). Food insecurity causes psychosocial stresses that are harmful to mental health and can increase susceptibility to other acute and chronic diseases (Weinreb et al., 2002). Residential crowding, resulting from limited access to housing or from prohibitory housing costs, also contributes to psychosocial stress in a community (Krieger \& Higgins, 2002). Unequal access to basic resources such as food, water, housing and medical supplies may have repercussions for the entire community by decreasing social cohesion (Wakefield \& Poland, 2005). Social cohesion and collective efficacy help to defend a community against crime and vandalism (Kawachi, Kennedy, Lochner, \& Prothrow-Stith, 1997) and provide social resources that buffer the negative health effects of being resource deprived (Sampson, Raudenbush, \& Earls, 1997) (see Section 2.4). 


\subsection{Social Services}

Communities with local access to health care, emergency and security services, good educational opportunities and social support systems such as welfare and social security are more likely to have good health (Cheadle et al., 1991). Access to these social services increases opportunities to obtain necessary resources (discussed above) and provides a buffer against volatile economic situations. Important issues include presence of these services, physical proximity to communities, cost and distribution.

Mechanisms by which social services affect community health include the provision of basic human needs (e.g. food, shelter, medications) or the means by which people meet those needs (e.g. employment or supplementary income). For example, communities that lack access to good quality health services may have higher burdens of disease because sick individuals will delay seeking care or will turn to alternative options, such as traditional healers or self-treatment (Chen et al., 2004; Meerman et al., 2005). Delayed treatment can have serious health consequences. For example, Gambian children presenting with severe malaria were significantly more likely to have delayed seeking treatment by more than four days than were those presenting with mild malaria (Meerman et al., 2005). Furthermore, self-medication may encourage drug resistance, as has been observed with malaria (Evans et al., 2005). Because poor or nonexistent welfare services can lead to increased poverty, malnutrition, homelessness, and starvation (Marmot, 2002) as well as reduced access to good education, such services have long been considered a "fundamental" determinant of health (Adler \& Newman, 2002; Adler \& Ostrove, 1999; Link \& Phelan, 1995). Education also may affect health by increasing knowledge of healthy behaviors and by increasing employment opportunities that provide income to meet basic health needs (Ross \& Wu, 1995). Individuals with better education live longer and suffer less morbidity than do their more poorly educated counterparts (Bobak, Hertzman, Skodova, \& Marmot, 1999; Hemingway, Shipley, Macfarlane, \& Marmot, 2000; Lynch, Kaplan, Salonen, Cohen, \& Salonen, 1995). Research by Winkleby and others (1992) revealed that even after controlling for the effects of income and occupation, education reduced risk of cardiovascular disease. Emergency services provide urgent care, which can lessen population morbidity and mortality. Security services such as fire fighting and policing help to deter crime and violence, which have serious implications for health. For example, the 1975 fiscal crisis in New York City led to a $20 \%$ reduction in the number of city police employees, which likely contributed to the homicide epidemic of the 1980s (Freudenberg, Fahs, Galea, \& Greenberg, 2006).

\subsection{Physical Environment}

Environments have long been recognized to play an important role in population health, from the ancient Greek's association of malaria with swamps to the miasma theorists purporting that squalid living conditions caused illness. With the advent 
of germ theory and the advancement of modern epidemiologic methods and statistical tools, our understanding of relationships between environmental conditions and health outcomes has deepened. We now recognize that forces at many levels shape environments and associated diseases. Global climate patterns influence temperature, precipitation, and extreme weather events; accumulating evidence suggests that human behaviors, such as the expanding use of fossil fuels, are causing rapid changes in climate (Vitousek, Mooney, Lubchenco, \& Melillo, 1997). Similarly, air and water pollution are affecting the quality of local, national and global environments and are shaped by human behaviors at each of these spatial/political scales. At the community level, environments are defined in part by physical conditions, which are affected by local, state or federal policies, such as zoning laws (Schilling \& Linton, 2005), as well as by human behaviors and actions such as vandalism (Ross \& Wu, 1995). The range of health indicators influenced by the built environment is vast and includes mental health (Weich et al., 2002), sexually transmitted infections (Cohen et al., 2000; Cohen, Mason et al., 2003), crime and violence (Newman, 1986; Sampson et al., 1997), substance abuse (Galea, Rudenstine et al., 2005), cardiovascular disease (Diez Roux, 2003) and physical activity (Frumkin, 2002), to name a few. Local environments, including homes and workplaces, may be sources of exposures to toxic substances, allergens or poor air quality (Bruce et al., 2000). Aspects of the outdoor environment are recognized as contributors to increased injury (Moore, Teixeira, \& Shiell, 2006) or breeding of disease spreading vectors (McMichael et al., 1999; Moore, Gould, \& Keary, 2002).

Community-level environmental characteristics and their potential health effects range in complexity and diversity. Climatic factors recently have drawn the attention of epidemiologists as measurement and analytic tools have improved. Greater climate extremes and global climate changes create or destroy microhabitats for many organisms that affect people's daily lives. Some changes may be beneficial, but most are expected to challenge efforts to improve health, particularly in developing countries. For example, insects that serve as vectors for various infectious diseases may become more abundant or widespread with global warming. One example is the possible increased range of malaria into previously uninfected highland regions (Bouma, Dye, \& Van der Kaay, 1996; Loevinsohn, 1994; Zhou, Minakawa, Githeko, \& Yan, 2004). Climate change, including extreme events, has been associated with other infectious diseases as well, such as cholera (Pascual, Rodo, Ellner, Colwell, \& Bouma, 2000), cryptosporidiosis (Atherholt, LeChevallier, Norton, \& Rosen, 1998), and other water-borne diseases (Curriero, Patz, Rose, \& Lele, 2001).

Similarly, changes in precipitation and temperature may affect local agricultural yields, thereby affecting food availability with all of the accompanying health implications (Fischer, Shah, Tubiello, \& van Velhuizen, 2005). As another example, temperature extremes may have direct effects on mortality, especially for poor, elderly or otherwise disadvantaged individuals. A heatwave in Chicago in July of 1995 resulted in 460 excess deaths that disproportionately affected African Americans and bed-ridden individuals (Semenza et al., 1996). In southern Chile, 
exposure to UV-B radiation due to the proximity to the Antarctic ozone hole has been linked to increased sunburn and photosensitivity (Abarca, Casiccia, \& Zamorano, 2002), and increases in skin cancer rates have been predicted (Jones, 1987). Limiting outdoor activities might protect against these health risks, yet this may cause other morbidities, such as obesity and diabetes, due to decreased physical activity (Gracey, 2002; McMichael, 2000). Many health effects of the built environment are certainly mediated by forces of the social environment.

\subsection{Social Environment}

Environments are not only physical but are also social. Social environments shape our interactions, our beliefs and our behaviors, all of which have health effects. To complicate matters, social environments likely interact with physical environments in their relationships with population health.

Aspects of the social environment that are likely to influence human health include social disorganization, social resources (including support and capital), social contagion, spatial segregation and inequality. The theory of neighborhood social disorganization, arising from sociological research of urban Chicago in the 1940s, posits that social disorder is conducive to deviant behavior and crime (Shaw \& McKay, 1942). This theory hypothesizes that social disorder originates from lack of social control, low density friendship networks, and lack of participation in local organizations (Sampson \& Groves, 1989). More recent research has shown that communities with high social disorganization are more likely to suffer from violence, victimization and homicide (Sampson et al., 1997), as well as coronary heart disease (Sundquist et al., 2006). Social disorganization may arise from inequalities in levels of deprivation and lead to anomie, defined as strain caused by disparate levels of attainment within a community (Kawachi, Kennedy, \& Wilkinson, 1999). Social strain not only encourages deviant behavior and crime (Agnew, 1992), but also has been shown to be associated with increased homicide and cardiovascular mortality (Cohen, Farley, \& Mason, 2003). Social strain may also cause physiological stress responses, which have well established links with mental and physical health (Elliott, 2000; Latkin \& Curry, 2003; Ross \& Mirowsky, 2001).

Social resources, including social support and social capital, are recognized to provide better coping mechanisms for difficult situations and are therefore associated with better health (Kawachi \& Berkman, 2001; McLeod \& Kessler, 1990). Social capital is also likely to help buffer negative health effects of social disorder by providing economic and social support (Sampson et al., 1997). Negative associations have been found between social capital and mortality (Kawachi et al., 1997; Skrabski, Kopp, \& Kawachi, 2004) and violent crime (Kennedy, Kawachi, Prothrow-Stith, Lochner, \& Gupta, 1998) and positive associations between social capital and self-reported health (Subramanian, Kim, \& Kawachi, 2002).

Social contagion, or social influence, is thought to affect health by the sharing of behaviors and attitudes among members of social networks, which can have both positive and negative health effects. These social norms are important in the 
transmission of infectious diseases, such as sexually-transmitted infections (STIs) and HIV (Pick \& Obermeyer, 1996; Wellington, Ndowa, \& Mbengeranwa, 1997), as well as in the spread of behaviors such as suicide (Phillips \& Carstcnsen, 1986) and criminality (Jones \& Jones, 1995).

\subsection{Population Heterogeneity}

The spatial distribution of racial and ethnic groups or groups of different socioeconomic status may contribute to the determination of population health. From an economic viewpoint, segregation leads to homogeneity of resources, where those with low socio-economic position cannot access the resources that benefit more affluent individuals. Segregation by socio-demographic characteristics is known to accompany differential exposure to poor quality environments, including toxins, crime, violence, poverty and infectious diseases (Cohen, Mason et al., 2003). Poor, segregated populations have restricted access to health care services, shortages of health care providers and many under- or un-insured individuals (Mayberry, Mili, \& Ofili, 2000). Finally, segregation and income inequality can cause both perceived and actual inequity, which erodes social trust and diminishes social capital with the resulting health effects as discussed above. This process may be enhanced by spatial proximity of the rich and the poor (Kaplan, Pamuk, Lynch, Cohen, \& Balfour, 1996; Kawachi et al., 1997; Mayberry et al., 2000).

In contrast, spatial heterogeneity of socio-economic groups encourages diversity and allows an opportunity for resource sharing. Wealthier individuals may be encouraged to use their money and power to improve the access and distribution of resources needed for good health. This heterogeneity may also provide access to broader social networks, including positive role models and salubrious social norms. For example, unequal distribution of education in communities in New York City has been shown to have salutary effects for all residents, suggesting benefits of actions of highly educated individuals (Galea \& Ahern, 2005). However, heterogeneous social environments may encourage social strain by providing images of unachievable aspirations to those with poor access to resources and few opportunities for advancement (Kawachi et al., 1999; Sampson \& Groves, 1989).

\section{National-Level Processes}

A substantial amount of epidemiologic research has examined the role of globalization in shaping population health at the national level. Cross-national comparisons of health indicators have investigated the effects of national income (Dollar, 2001; Lynch, Smith, Kaplan, \& House, 2000; Weisbrot et al., 2002), mode of governance (Navarro \& Shi, 2001), and average educational attainment (Williamson \& Boehmer, 1997), among others. We add to this body of literature by explicitly hypothesizing mechanisms through which aspects of nations may influence health and the extent to which this is mediated by the community-level determinants of health discussed above. 


\subsection{Infrastructural Resources}

Availability of national resources and the distribution of those resources have great potential to influence population health. To the extent that money can finance infrastructural development, overall national income becomes an important element in this equation. National incomes are based on myriad factors, including exploitable natural resources, position in the global economy, import tax policies, and domestic tax policies. Income alone, however, does not equal infrastructure. National governments make choices about how income will be spent.

Explicit pathways through which national infrastructural resources may affect population health are many, making a thorough cataloguing beyond the scope of this chapter. We present a few examples for illustrative purposes.

Underinvestment in national health services can be manifest through scarce health clinics, hospitals or health providers, inadequate accessibility, or poor quality of available health services (Chen et al., 2004). Low salaries and unpleasant work conditions lead health providers in some low-income nations to migrate to better opportunities (Brown \& Connell, 2004). Such "brain drain" compounds the negative health effects of underinvestment in health services by reducing the number of health providers, as well as the quality of available care (Brown \& Connell, 2004; Chanda, 2001; World Health Organization, 2006). Some evidence exists that perceived poor quality of health services leads to underutilization of these services and increased use of alternative resources (Haddad \& Fournier, 1995; Segall, 2000). Alternatives include traditional healers or self-medication, which may increase chances of inappropriate or insufficient treatment, possibly also encouraging drug resistance for certain pathogens (Evans et al., 2005).

Underinvestment in social resources at the national level is also an important predictor of population health (Davey Smith, 1996; Wagstaff, Bustreo, Bryce, \& Claeson, 2004). Societies with a large proportion of uninsured or underinsured individuals who cannot afford health care costs are at risk for sustained transmission of communicable diseases as well as high burdens of disability due to untreated chronic diseases (Hadley, 2003; Institute of Medicine, 2002). A lack of support for people who are unemployed, unable to work, or underpaid increases poverty levels. Poverty is recognized as an important determinant of population health through a vast array of mechanisms, including increased susceptibility to disease due to poor nutrition (Wagstaff et al., 2004) and incomplete vaccination (Klevens \& Luman, 2001), increased contact with disease-causing agents due to unhealthy environments and crowding, and prolonged duration of disease due to lack of appropriate treatment (Wagstaff et al., 2004).

Finally, underinvestment in environmental infrastructure, including roads, the built environment, water and sewage systems, and electricity, also holds great potential to reduce population health. For example, unpaved roads on a Native American reservation in New Mexico were shown to discourage timely access to health services in children with meningitis (Williams, 1987). Lack of potable water and sewage and waste disposal facilitates the spread of infectious diseases 
(World Health Organization, 2004) and increases the stress and physical strain for families (especially women and children) who must transport water long distances to their homes (Cosgrove \& Rijsberman, 1998; United Nations, 2005). Additionally, poor water quality and inadequate sewage infrastructure may create breeding sites for vectors that transport infectious disease agents (Keating et al., 2003).

\subsection{Employment}

The availability and nature of employment opportunities at the national level have been shown to affect population health, especially overall mortality (Gerdtham \& Johannesson, 2005) and suicides (Dooley, Fielding, \& Levi, 1996). National employment trends may be examined by several characteristics. Most commonly, unemployment rates are reported as an indication of the percentage of a nation's population that is unwillingly jobless. Another important element of employment is salary, with information coming from both minimum wages mandated by national law and the range and distribution of salaries in the country. Additionally, the permanence or reliability of employment and the type of job and associated work conditions are national employment trends that shape population health.

Unemployment, underemployment and nonstandard employment affect population health through several mechanisms. First, joblessness usually accompanies loss of income, which limits the purchase or attainment of necessary resources. Unemployment or part-time or seasonal employment may lead to loss of medical insurance to cover disease prevention and treatment (Ostry \& Spiegel, 2004). Another important mechanism by which unemployment affects health is by elevating acute stress or creating situations of chronic stress. A large body of literature on the health effects of threatened job loss in factory workers reveals many negative outcomes, such as elevated blood pressure, increased depression and anxiety (Cobb \& Kasl, 1977; Ostry \& Spiegel, 2004), or diminished mental health and increased stress (Hamilton, Broman, Hoffman, \& Renner, 1990). A Danish study conducted on bus drivers with restructured and contracted out jobs (less stability) found high levels of urinary cortisol and elevated blood pressure (Netterstrom \& Hansen, 2000). Non-standard work (part-time, contingent) may also increase risk of stress and workplace injury (Quinlan, Mayhew, \& Bohle, 2001). A complete review of the health effects of stress is beyond the scope of this paper, but it includes reduced immunity to infectious diseases (Cohen, Tyrrell, \& Smith, 1991; Takkouche, Regueira, \& Gestal-Otero, 2001), increased adoption of unhealthy behaviors (smoking, drinking, etc.) (Adler \& Newman, 2002) and increased susceptibility to inflammatory diseases (Korte, Koolhaas, Wingfield, \& McEwen, 2005; McEwen \& Seeman, 1999).

Even reliable employment with livable wages may affect population health through the nature of the work and the work environment. Poor work environments place workers at risk for injury, respiratory disease, exposure to toxins and infectious agents (Loewenson, 2001). For example, in African countries annual injury rates for occupations such as mining, forestry and transport all exceed 
30 injuries per 1000 workers (Loewenson, 1998). The risk for such negative health outcomes at the national level depends greatly on the nature of available jobs. Current global trends concentrate the risks of poor quality work environments and insecure, low paying, low quality jobs in less industrialized countries (Loewenson, 2001). Women are disproportionately affected by these trends, which compound the health affects of the social and economic marginalization that they experience. A clear example is female employment in export processing zones. These jobs provide low wages, exposure to toxic chemicals and substances, long work hours, physical brutality and psychological stress (Hippert, 2002; Loewenson, 2001). The health effects of child labor are also important. An estimated 211 million children under the age of 14 and 352 million under the age of 17 are part of the worldwide workforce, most in developing countries (Habenicht, 1994; International Program on the Elimination of Child Labor, 2002). Child labor detracts from the benefits of education and has been shown to be associated with stunting and wasting (Hawamdeh \& Spencer, 2003).

\subsection{Income Growth}

National income growth is generally assumed to be beneficial for population health (Marmot, 2002). More income means more resources that can be used to meet the health needs of the population. In reality, the association between national income growth and health is much more complex and depends on a wide array of contextual factors. The important factors likely include fiscal and regulatory policies, level of dependence on imports and exports, level of indebtedness and loan stipulations, and baseline income level as well as the distribution of the income (Ayala-Carcedo \& Gonzalez-Barros, 2005). Considerable economic literature on globalization argues that opening economies to the global market stimulates economic growth, which, in turn, reduces poverty (Dollar \& Kraay, 2002; Frankel \& Romer, 1999). Assuming that poverty reduction is good for health, it logically follows that opening national economies will lead to healthier nations. There are several problems with this argument. First, it is controversial whether opening economies to the global market promotes national income growth (Cornia, 2001). Support for this hypothesis is informed by Dollar and Kraay's (2002) findings. Their work relies heavily on data from India and China, presumably because those countries represent such a large percentage of the world's population; however, the experiences of Indian and Chinese economies post-trade liberalization are not necessarily representative of all nations. Second, population health indicators seem to be more sensitive to changes in national incomes with lower baselines (Marmot \& Wilkinson, 2001). Globalization's effect on income inequalities at both the global and national levels has been hotly debated (Lynch et al., 2004; Subramanian \& Kawachi, 2004; Wilkinson \& Pickett, 2006) as has the relative importance of income inequality versus income growth on health outcomes (Lynch et al., 2000; Ross \& Mirowsky, 2001). While readers can draw their own conclusions in this debate, we present several mechanisms by which national income growth may influence population health. 
Income growth provides government revenues and other societal resources needed to supply goods and services (Dodgson, Lee, \& Drager, 2002; DiazBonilla, Babinard, \& Pinstrup-Andersen, 2002). Income growth may stimulate national labor markets, thereby providing more jobs for the population. Dependable employment with livable wages provides means for people to purchase necessary resources such as food and health care (Collins, 2003). Being securely employed also encourages feelings of self-worth and increases social cohesion (Sen, 1997). However, if national income growth is based on volatile economies, employment may be insecure and layoffs unexpected (Sen, 1997). Various potential health effects of job insecurity were described in Section 3.2. Another result of volatile income growth is sudden unexpected reductions in household wealth, which may result in children leaving school to join the workforce and sometimes engaging in high risk jobs such as prostitution (Cornia, 2001). Sudden decline in wealth may also compromise health by reducing quantity and quality of nutrition (Cornia, 2001).

\subsection{Population Density}

Population density has long been associated with population health. Historic studies of environmental determinants of disease in urban settings during the era of industrialization in Europe comprise the backbone of modern social epidemiologic science. Conditions during that era, including rapid industrial development, the breakdown of traditional social and ideological structures, and urban blight followed by suburban flight of the wealthy, led to concentrated poverty, crowding, death and disease in many urban settings (McMichael, 2000; Szreter, 1997). Although these trends may be less relevant for societies in Western Europe and other developed nations today, they are reality for nations in the developing world. Population density is rising in many parts of the world due to rural-tourban migration (urbanization) and population growth (McMichael, 2000). People searching for economic opportunities, employment and a better standard of living, combined with destruction of habitats in rural areas, are among the plethora of reasons for migration to cities in the developing world (see Section 4.3). By 2007 it is estimated that over half of the world's population will live in urban settings, contrasted with only $5 \%$ at the beginning of the 19th century (United Nations Department of Economic and Social Affairs, 2003). The proportion of urban dwellers is expected to grow to $60 \%$ by 2030 (United Nations Department of Economic and Social Affairs, 2003). Additionally, the size of urban populations is continuing to expand. From 1940 to the present, the number of "megacities" with more than 10 million inhabitants rose from one (New York City) to fifteen (Satterthwaite, 2000).

Among urban residents, crowding may occur due to poverty or lack of habitable physical space. Evidence suggests that population density may predict many health effects, including infectious diseases such as tuberculosis (Antunes \& Waldman, 2001) and acute respiratory infection (Lee, Jordan, Sanchez, \& Gaydos, 2005), chronic diseases such as stomach cancer (Barker, 
Coggon, Osmond, \& Wickham, 1990), and poor mental health (Lepore, Evans, \& Palsane, 1991). In addition, people living in dense populations experience higher rates of violent death (Wallace \& Wallace, 1998) and injury (LaScala, Gerber, \& Gruenewald, 2000) than do less dense populations.

Illuminating the mechanisms through which increased population density may affect population health is more challenging than showing an association exists. Perhaps the most intuitive relationship to discuss is that between population density and risk of infectious disease. High population density means that individuals will have a greater number of contacts with others. Contact rates are an essential parameter in the risk of infectious disease transmission, particularly for those diseases with person-to-person modes of transmission (Anderson \& May, 1991). A higher contact rate generally corresponds to more transmission, all other factors being equal. Therefore, areas with high population densities are more conducive to disease spread. In addition, populations living in crowded conditions are also often those with the fewest resources (Baum, Garofalo, \& Yali, 1999). Crowding in situations of poor sanitation increases the spread of infectious disease through increased risk of exposure to infectious agents in the environment (Krieger \& Higgins, 2002). These factors contribute to the ongoing cholera pandemic, especially, for example, in areas such as the peri-urban slums of Brazil (Nations \& Monte, 1996). Similar concerns appear in other parts of the world, such as Russia, where overcrowded prisons and insufficient public health measures contribute to multi-drug resistant tuberculosis (TB) (Holden, 1999). In Saudi Arabia, Muslim pilgrims gather annually during the Hajj, increasing risks of meningococcal outbreaks, hemorrhagic fever and even SARS (Ahmed, Arabi, \& Memish, 2006), and in Palestinian refugee camps in the Gaza strip, crowding and poor sanitation contribute to intestinal parasites and diarrheal diseases (Abu Morad, 2004). Where dense populations coexist in poverty and inadequate infrastructure, environments may also increase the risk of vector-borne diseases by increasing contact with vector breeding sites (Afrane et al., 2004; McMichael, 2000).

Urban settings have been linked to high rates of certain chronic diseases, including cardiovascular disease and type II diabetes (Diez Roux, 2003; McMichael, 2000). These associations might be explained in part by aspects of the built environment that allow easier access to energy-dense foods and a decline in physical activity (Handy, Boarnet, Ewing, \& Killingsworth, 2002). Concentration of cars, trucks, and buses in densely populated areas elevates noxious emissions exposure. Urban traffic is therefore linked to increased risk of respiratory disease (McMichael, 2000), not to mention the risk of transportation related accidents (LaScala et al., 2000). Furthermore, dense populations tend to have higher rates of suicides, violent crimes, drug use and mental diseases due to social tension, competition for resources, lack of social cohesion or psychosocial stress (Galea \& Vlahov, 2005). Stress is also a risk factor for many chronic conditions such as atherosclerosis and depression (McEwen, 2004) and is associated with lowered immune response, making it a risk factor for infectious disease as well (McEwen \& Seeman, 1999). 


\subsection{Governance and Policies}

National policies may include health policies as well as other legislation affecting the social and environmental domains of society. National health policies dictate to what extent national governments have control over and responsibility for providing health services to the population. Some countries support a nationalized system of health care whereby the government both pays for and provides health services. Other nations have privatized health care such that individuals are responsible for meeting their health care needs through the private market. Even nations with privatized health care usually subsidize the costs of such services for certain members of the population (the elderly or poor) as in the Medicare and Medicaid programs of the US.

Other aspects of health policy important for population health include economic decisions about resource allocation. Governments may decide to invest in the development of primary care and disease prevention services to maximize cost-benefit indices, or tertiary care and treatment may be prioritized for fund distribution. Judgments must also be made about investment in research and development of medications, technologies and vaccines. Resource allocation decisions about health services relative to other national services are necessary. These decisions are political and vary greatly by nation and ideologies (Coburn, 2004). They are likely to influence health by determining what kinds of services are available, how accessible and affordable they are and what sectors of the population have access (Mehrotra, 2006). National policies regarding other domains of public life, including welfare, education, social security, subsidized housing, and employment, are also likely to play an important role in determining both quality of population health, as well as distribution of health outcomes in the population (Marmot, 2002). Finally, political ideologies at the national level have been hypothesized to influence health by differential support of welfare policies and recognition of and attention to the needs of the population (Franco, AlvarezDardet, \& Ruiz, 2004). For example, a recent study found a link among good governance measured by accountability, political stability, absence of violence, government effectiveness, regulatory quality, rule of law and the control of corruption and national HIV prevalence (Menon-Johansson, 2005; Widdus, 2005)

Economic decisions regarding resource allocation and distribution are likely to influence population health through various pathways with resounding health effects. For example, Freudenberg and colleagues (2006) describe the impact of city, state and federal budget cuts on a TB/HIV/homicide combined epidemic in New York City during the 1980s and 1990s, which they term a "syndemic". These authors argue that budget cuts undermined the ability of city health and social service infrastructures to respond to health emergencies and emerging health threats; reduced education, policing and drug treatment services; and amplified social trends. These factors then contributed to increased risk of violence and disease in the population. Other authors have posited that national policies influence health through the mechanisms of social capital, empowerment and access to information, which are differentially accorded to populations living under different 
political economic systems (Franco et al., 2004). Perhaps most relevant to globalization and health are arguments delineating relationships between government policies shaped by capitalist ideology and health outcomes mediated by increasing income inequalities and lowered social cohesion (Coburn, 2000; Muntaner \& Lynch, 1999). National governance therefore affects population health both through national-level and community-level pathways.

\section{Global-Level Processes}

Epidemiologic research on the health effects of global-level factors is inadequate. We consider global-level factors to involve the processes of globalization that extend beyond national borders (outlined in Section 1.1). Understanding the differential effects of national-level factors on health in the global system will enhance opportunities for effective health interventions through a focus on global-level structural changes to achieve sustainable improvements in health.

\subsection{Global Trade}

One important component of globalization is increased trade in goods and services both between and within nations. Exchanges of goods and services shape nations' economies through imports and exports and levied taxes. In effect, trade serves to redistribute commodities and wealth throughout the world, and it is the patterning of this redistribution and its associations with health that interests us. Some global health researchers seek to determine whether trade and increased access to material resources leads to more equitable redistribution of wealth or to a concentration of wealth in the hands of a few.

The nature of the dynamic global exchange of resources is likely to be affected by enduring conditions such as geographical location, location of exploitable natural resources, and history of past interactions in the global market (Gallup, Sachs, \& Mellinger, 1999; Moore et al., 2006). For example, Moore et al. (2006) found that tropical and landlocked countries were more likely to have higher infant mortality rates than were other countries even after adjusting for the position of the country in the world system. Increasingly, nations are becoming dependent on the global economy and on trade with others for the well being and survival of their citizens.

Increased trade provides an opportunity for the exchange of both essential, salubrious resources and those that may be deleterious for health. Commerce in essential goods, such as food, improves access to good nutrition in areas of the world with poor quality agricultural land or short growing seasons (Hawkes, 2006; Shetty, 2006). Trade in medicinal products such as vaccines and pharmaceuticals helps to protect the quality and duration of life in areas of the world without the technological or industrial capabilities to produce their own supplies (World Health Organization, 2004; Widdus, 2005). Exchanges in services such as health care and education also provide opportunities to improve population health in disadvantaged nations (Bettcher, Yach, \& Guindon, 2000; Widdus, 2005). However, expanding 
markets have also provided a venue for the dissemination of goods that are deleterious to health such as tobacco, illegal drugs and weapons (Huynen et al., 2005; McMichael \& Beaglehole, 2000; Yach \& Bettcher, 2000). In addition, global trade creates an opportunity for contaminated products or infectious agents to cause widespread illness, facilitating the speed and distance of disease outbreaks. For example, the transportation of Aedes aegypti mosquito eggs in used tires being shipped across the oceans led to the rapid expansion of dengue virus infections worldwide (McMichael, 2000). Indeed, a multitude of food-borne pathogens are transported globally each year; for example, Cyclospora cayetanensis in raspberries imported to the US caused an outbreak of diarrheal disease in 1996 (Centers for Disease Control and Prevention (CDC), 1996).

The dynamics of global trade are complex and influence health at the same time that they are influenced by national-level and community-level factors. For example, increased global trade does not ensure even distribution of commerce throughout the world (Subramanian, Belli, \& Kawachi, 2002). Some countries may be denied access to the world market due to national-level factors such as governance, lack of marketable products or lack of income with which to purchase commodities (Ayala-Carcedo \& Gonzalez-Barros, 2005). These countries are unlikely to experience the health benefits of increased global trade. Minimal access to the global market may also affect population health by restricting the growth of national economies, which in turn limits funds available for infrastructure development and health services at the community level. Limited national funds for health workers salaries also contributes to poor population health as doctors, nurses, teachers, and other skilled workers emigrate in search of better opportunities, thereby depriving communities of quality health services (Brown \& Connell, 2004; World Health Organization, 2006). Even countries experiencing positive income growth due to trade activities on the global market may experience poor population health outcomes if the money is not used to provide necessary social services or infrastructure development. Additionally, unequal distribution of resources at the community level may contribute to deterioration of the physical and social environments, which has deleterious health effects as previously discussed (see Sections 2.3 and 2.4).

\subsection{Income Distribution}

Unequal distribution of goods and services contributes to unbalanced global trade as well as to income inequalities among nations. Why do we care about the distribution of wealth? We know that on an individual level rising income leads to better nutrition, lower child mortality, and better maternal health (Filmer \& Pritchett, 1999; Pritchett \& Summers, 1996). Whether this relationship between income and health holds at the population level is less clear. Some economists argue that nations with more open trade policies experience more rapid income growth, which leads directly to better population health (Dollar, 2001; Dollar \& Kraay, 2002). Others provide evidence that increased global integration leads to increasing inequality both in wealth and in health and both within and between nations 
(Coburn, 2000; Lynch et al., 2004; Wilkinson \& Pickett, 2006). The debate on income inequality and its potential health effects is multifaceted. Does globalization encourage increasing income inequality, and if so, is this inequality within nations, between nations or both? Is income inequality bad for population health? What are the mediating factors of the income inequality-population health relationship?

Global income distribution may shape population health through its influence on global, national, and community level factors. At the global level, rising income inequality encourages migration and fosters conflict (Wade, 2004). Coburn (2000) hypothesizes that neo-liberal economic policies affect health by encouraging intra-national income inequality and decreased social cohesion. At the national level, unequal global income distribution provides differential access to necessary goods and services (Baum, 2001). These goods and services help to determine national income which affects community-level access to resources necessary for good health through providing the means for infrastructural development, provision of social services, and provision of employment opportunities. Differential global income distribution therefore affects the local distribution of health resources. Sizeable income inequality also suppresses income growth at the national level (Cornia, 2001) and reduces the rate of poverty alleviation (Ravillion, 2001).

The health effects of global income inequality may be moderated or mediated by national-level characteristics, such as national policies and type of governance. For example, Navarro and Shi (2001) found that countries with predominantly social democratic government traditions between 1945 and 1980 experienced more economic growth, lower levels of income inequality and unemployment, and lower infant mortality rates than did countries with liberal or fascist government traditions. Community-level characteristics may act as mediators of the health effects of income distribution as well. For example, poor communities in nations with high income inequality may experience reduced social cohesion and the associated health effects due to a lack of employment opportunities and higher poverty (Wade, 2004).

\subsection{Population Movement}

Population movement is another important component of globalization with significant health implications. Improvements in transportation technology in the past century have drastically amplified the speed and distance of human travel (Smolinski et al., 2003). Ease of travel, both domestically and internationally, has lead to an unprecedented magnitude of travelers both for business and for tourism (World Trade Organization, 2005). Yet any economic benefits must be evaluated in the context of increased transport and transmission of infectious diseases (Wilson, 2003). Migration is another reason for international and domestic travel. Motivations for migration are diverse and include search for better economic situations, flight from violent conflict or repressive government, and pursuance of educational opportunities, to name a few. Rural to urban migration, also 
known as urbanization, is an increasingly important phenomenon in the consideration of determinants of population health (Galea, Freudenberg et al., 2005; McMichael, 2000). The driving factors behind trends in population movement also change population demographics. For example, in developing countries, rural villages are aging due to the rural-urban migration of youth looking for work in the cities (Stloukal, 2001). In many villages in Southern Africa, men leave to work in the mines (Quinn, 1994), altering the male to female ratio in the communities. In Mexico and Asia it is women who leave the home to work in the export processing zones (Hippert, 2002).

Mobility of human populations has the potential to affect health through a variety of mechanisms. At the global level, population movement facilitates spread of culture and technology, which can be beneficial for population health by expanding health knowledge and encouraging healthy behaviors (Frenk, 2005). However, the globalization of culture has been seen as "Westernization" or "Americanization", which threatens other ways of life and can sometimes lead to conflict (Frenk, Sepulveda, Gomez-Dantes, McGuinness, \& Knaul, 1997; Holton, 2000).

The effects of global population movement on population health may be mediated by national factors. Take, for example, the enhanced spread of infectious diseases facilitated by novel patterns of human to human contact, as well as by changing eco-social environments (McMichael, 2000). The magnitude of morbidity and mortality due to increased infectious disease spread is likely to depend on national capacity to respond to disease outbreaks, which is a function of income, infrastructure and health knowledge and resources. The recent SARS pandemic provides an appropriate opportunity for comparison of population health outcomes for affected nations with different mediating characteristics. We might compare the SARS mortality rates in Canada, China and Singapore as a function of national infrastructure or of per capita income. Community-level effects of the spread of infectious diseases due to increased population movement are demonstrated by the SARS outbreak in Toronto, Canada. The social environment of the city was affected by the psychosocial effects of fear and local resources were disrupted by the economic effects of isolation and quarantine (Gupta, Moyer, \& Stern, 2005; Hawryluck et al., 2002).

Another example of population health effects of human mobility involves the dynamics of population flows. At the global level, population movement is increasing, but this movement is not uniform among nations or regions of the world. The classic example is that of "brain drain", in which highly educated or skilled individuals from poor countries are recruited for employment in more wealthy nations. This differential migration exacerbates national and community-level problems of poor education, poor access to health services, and poor quality health services in the neediest regions of the world (Brown \& Connell, 2004; World Health Organization, 2006). At the national level, changing demographics associated with mobile populations include rapid urbanization, especially in the developing world (Galea \& Vlahov, 2005; McMichael, 2000; Moore et al., 2006). This phenomenon, coupled with high fertility rates, threatens population health by increasing pressures on limited national and community resources (McMichael, 2000). 
At the community level, the physical environment is affected; poor urban infrastructure fails to provide potable water and sewage facilities to these burgeoning populations, resulting in increased disease burdens (McMichael, 2000). Local conflicts may also arise from competition over limited food or arable land. Psychosocial stress resulting from high population densities and difficult living conditions may also seriously influence community health outcomes (McEwen \& Seeman, 1999).

\subsection{Global Governance}

All the aforementioned components of globalization are affected, to some extent, by the nature and extent of global governance. Governance is defined by Dodgson et al. (2002) as "the actions and means adopted by a society to promote collective action and deliver collective solutions in pursuit of common goals," and has typically been conceptualized at local and national levels. As trends of globalization change our delineation of societies, the concept of governance must take on a new dimension: Increasingly globalized societies need governance on a global scale.

Pursuit of global governance is challenging due to the historical precedent of national sovereignty, the right of each nation to govern its citizens. Reorganizing governmental hierarchies and establishing common goals for the entirety of the world's people is not an easy task. Some forms of governance do exist on a global scale, however. The World Trade Organization (WTO) has developed trade agreements that guide exchanges in goods and services among nations (Kinnon, 1998). Two examples include the Agreement on Trade-Related Aspects of Intellectual Property Rights (TRIPS) and the General Agreement on Trade in Services (GATS). TRIPS establishes minimum standards of protection of intellectual property, thereby safeguarding industrially applicable inventions, such as pharmaceuticals, under patent laws. GATS regulates trade in health services. The World Health Organization (WHO) also governs global health through the legally binding International Health Regulations. These regulations aim to reduce global disease spread with minimal trade interference.

Before discussing the mechanisms through which global governance affects population health, we must mention one key caveat. It is questionable to what extent governance has truly globalized despite the existence of international organizations such as the WTO and the WHO. These organizations are charged with defending the trade interests and health interests, respectively, of member states. However, not all nations are members of these organizations despite the fact that all nations share trans-border health risks. Additionally, member states do not all have equal representation in these organizations. Many poor countries cannot pay the fees needed to send representatives to meetings (Bowman, 2004).

Mechanisms by which trends in global governance affect population health are many and varied. At the global level, international policies regulate trade in goods. As this partially predicts income distribution, governance, trade, and 
income are closely intertwined. At the national level, income mediates the effect of global governance on population health. A classic example is the debate over generic pharmaceutical production in developing countries that arose over the need for antiretroviral (ARV) medication for HIV. Under the TRIPS agreement created by the WTO, the production of patented medications was prohibited at the global level. The result was that national access to expensive medications was determined by national income; rich countries could afford to buy life-saving medication for their populations and poor countries could not. To pursue this example to the community level, countries with enough income to purchase limited supplies of ARVs might offer better health outcomes to high income communities that could afford the high prices. Alternatively, these nations might choose other distribution criteria, offering the medications to government employees or to those seeking care at a certain health facility. It is easy to understand how, in a community with high HIV prevalence, differential access to ARVs might erode social cohesion and trust (Bennett \& Chanfreau, 2005). High medication prices may also divert resources from other necessities, such as food and school fees, producing resounding population health effects.

Two other potential mechanisms are worth noting. An addition of a global dimension to governance of health issues may be counterproductive, undermining the authority and the ability of national governments to protect the health of their citizens (Collins, 2003). This argument can similarly be made for all neo-liberal trade policies in that the tenets of economic globalization, including decentralization, may lead to disempowered national governments (Coburn, 2000; Navarro \& Shi, 2001). Finally, in the current era of globalization, an increasing number of non-state actors (e.g., NGOs, private corporations, religious organizations) may influence health governance, thereby eroding national resources for addressing health issues (Dodgson et al., 2002). Despite the increasing influences of these non-state actors in health decisions, the WHO focuses its efforts on working with Ministries of Health of sovereign member states. Neglecting to bring NGOs and private sector actors into negotiations results in a lost opportunity for valuable input (Dodgson et al., 2002).

\subsection{Communications and Technology}

Global communications include radio, telephone, television, and media in general, as well as the internet. The scope of global communications is enormous; in 2004 over 30 minutes per person were spent on international telephone calls worldwide, and $69 \%$ of the world's population was covered by mobile telephony (World Bank, 2006). In addition, the number of global internet users increased by $189 \%$ from 2000 to 2005, with more than one billion people now having access (Internet World Stats, 2006).

Enhanced global communications affects population health through the dispersion of ideas, information, knowledge and technologies. Telephone networks provide avenues for emergency communications and foster social connections between friends and families (Berkman, Glass, Brissette, \& Seeman, 2000). 
The internet provides opportunities for education and information sharing, which can lead to healthier behaviors and, perhaps, more informed and effective health interventions (Frenk, 2005). Nations and communities can use the internet to store and communicate health data and statistics, allowing more targeted and efficient use of resources (Frenk, 2005). Global media also may influence population health by informing individuals, communities and nations about global issues that may have local impacts and allowing an opportunity for prevention or intervention. Media coverage of global events allows collective awareness of political, social and ecologic realities across the world. Global media also presents the potential for views and ideologies of powerful people or groups to dominate and skew the objectivity of reporting of events of global importance.

Despite the rapid growth in global information technologies in recent years, some evidence exists that the gap in access to these technologies is widening, particularly between rich and poor nations as well as between rural and urban areas within nations (Arnett, 2002; United Nations Development Programme, 2001). This suggests that the relationship between global communications and population health may be mediated by various national and community level factors. We might consider the mediating effect of culture, for example. Research by Holton (2000) examines three cultural responses to the global information influx: homogenization, polarization and hybridization. Homogenization occurs when a local culture merges with global culture, a phenomenon sometimes called "Coca-Colonization" or "McDonaldization". This may result in adoption of poor health behaviors, such as smoking and drinking alcohol, as well as healthy behaviors, such as increased hand washing. Polarization consists of diametrically opposed cultural groups that create conflict and brew hatred for one another. In that such hatred ends in war or ethnic cleansing, the negative health implications are obvious. Finally, global communications may also lead to the formation of hybridized cultures, which incorporate elements from a variety of cultural sources. The health effects of hybridization of culture may be beneficial if it leads to enhanced understanding and cooperation among different local cultures. Some evidence exists to support the "politics of difference" theory, whereby group members become empowered by drawing upon identities and beliefs that are counter-hegemonic (Williams, Labonte, \& O'Brien, 2003). This empowerment may provide enhanced collective actions of communities to seek healthier environments and encourage healthier behaviors. In contrast, some individuals in a culture may resist hybridization while others support it, creating inter-group conflict and a dissolution of social trust and cohesion. One example involves intergenerational differences in responses to global media in Japan (Arnett, 2002). Attempts have been made to mathematically model the dynamic between global processes, such as population density, and the maintenance of cultural identities in order to quantify the potential for homogenization, polarization or hybridization of cultures (Hochberg, 2004). However, few have investigated how these cultural adaptations affect health outcomes, suggesting that much more research is needed. 


\section{Example Mechanisms}

Here we present three specific examples to illustrate mechanisms through which global factors exert influences on population health. Consider that these pathways are likely to be highly complex and multidirectional and aspects of national- and community-level environments may mediate or modulate the effects of global factors on health. In addition, one global factor may influence health outcomes via multiple pathways. We present simplified examples, which serve to highlight the logistical and methodological challenges, as well as the importance of including the global context in epidemiologic population health research.

\subsection{Diarrheal Mortality Rates}

A common theme presented in this chapter is the health importance of access to clean water. We may use community mortality rates due to diarrheal disease caused by unclean water sources to examine how population movement may influence one particular health indicator. In order to understand the causes of high rates of deaths due to diarrhea in a community we have to consider communitylevel factors that have been shown to be important predictors, such as the age distribution of the population, local environmental conditions (sanitation), breastfeeding practices, malnutrition, personal hygiene and access to medical supplies and services (such as oral rehydration solutions, ORS) (Feachem, 1984; Kosek, Bern, \& Guerrant, 2003; VanDerslice, Popkin, \& Briscoe, 1994). Limiting our study to community-level factors may be misleading, however. By including national-level variables, we might find that although community hygiene practices significantly predict diarrheal mortality rates at the community level, when we take national population densities into account, hygiene practices are no longer predictive. This might be because personal hygiene is associated with protection from infectious diarrhea-causing agents in countries with low population densities where these behaviors are mostly sufficient to protect against disease. In highly populated countries these behaviors may not be sufficient to provide protection (maybe due to high contact rates with the infectious agents). For example, high regional population densities have been found to be associated with greater child mortality rates in Zimbabwe (Root, 1997) and to be predictive of cholera outbreaks in Bangladesh (Myaux, Ali, Felsenstein, Chakraborty, \& de Francisco, 1997). Global factors may be essential in understanding and predicting the pathway between national population densities, community hygiene and population diarrheal mortality rates. National population densities may be highly dependent on global migration patterns and not just on domestic fertility rates as is the case in the United States, France and Germany (Cohen, 2003). This example demonstrates how our understanding of the underlying causality of health outcomes is improved by widening the scope of study to include the global context. 


\subsection{Maternal Mortality Rates}

Maternal mortality rates are one of the few standard measures of health used to compare health conditions across nations or regions. We argue that in order to study the factors that contribute to high maternal mortality rates it is important to investigate community-, national- and global-level conditions. For example, at the community level, past research has shown that maternal anemia, poor health care and lack of skilled birth attendants predict high maternal mortality (Rush, 2000). These factors are likely to be influenced by national-level factors such as infrastructural resources available for health services. Evidence for this surfaces from a study in which maternal mortality rates were shown to be negatively correlated with national health expenditures (Betran, Wojdyla, Posner, \& Gulmezoglu, 2005). The relationship between national health spending and maternal mortality rates may in turn be determined by global level factors such as integration into the global market. According to a report by Global Health Watch (2005), "many macro-economic factors that help to keep poor countries poor, by extension, keep levels of health care expenditure low." For example, for many developing countries well integrated in the global economy the 1979-1981 global increase in oil prices led to financial crises due to reduced trade revenues and greatly inflated debt service payments (Global Health Watch, 2005). Maternal mortality rates are therefore likely to be determined not only by local or national conditions, but also by global factors.

\subsection{Severe Acute Respiratory Syndrome}

One final example that illustrates the importance of global-level health determinants in studies of population health is the recent severe acute respiratory syndrome (SARS) pandemic that menaced the globe in 2002-2003. In examining the causal factors related to the SARS outbreak, community-level determinants have been shown to be crucial in the emergence of the disease in human populations. Some key factors that have been identified with SARS are densely populated communities and close, repeated contact with wild animals, especially palm civets (Paguna larvata) and raccoon dogs (Nyctereutes procuyoinboides) (Breiman et al., 2003; Poon, Guan, Nicholls, Yuen, \& Peiris, 2004; Webster, 2004). On a national level, China's deficiencies in health infrastructure allowed the emergence and continued spread of the disease without appropriate response measures (Liu, 2004). In contrast, Singapore rapidly introduced strict infection control measures resulting in low numbers of secondary cases (World Health Organization, 2003). This illustrates how national infrastructures and health policies can influence disease spread at the community level. At the global level, intercontinental travel facilitated disease spread (World Health Organization, 2003), whereas the existence of global health infrastructures and global communication networks allowed enhanced information exchange and rapid implementation of appropriate control and prevention measures worldwide (Fidler, 2004; Heymann, 2004). SARS provides a recent and fitting example of how global factors influence health at local levels and illustrates the importance of global perspectives in preserving population health. 
As these examples illustrate, asking questions about the global context of causal pathways leading to health and disease deepens our understanding of the eco-social mechanisms responsible and allows for more opportunities to intervene.

\section{Future Research}

The pathways through which community-, national- and global-level factors affect population health that are presented in our conceptual model and discussed above are far from exhaustive. Nevertheless, these examples are illustrative of the importance of context in public health research. We argue that the global context, hitherto largely overlooked in epidemiologic studies, is essential for fully understanding the determination of population health. Indeed, inclusion of global-level factors in epidemiologic analyses may reveal complexity of relationships between more proximal-level factors and health indicators that were previously thought to be simple and well characterized.

Clarification of research goals is of paramount importance in developing epidemiologic investigation of population health determinants in a global context. First, there is a need for identification of gaps in currently existing knowledge. We have presented some examples as illustration, but a more systematic examination of the literature should be undertaken. Second, research needs to focus on hypothesizing and testing specific pathways through which global factors affect health. The results of such analysis will enable policy makers to prioritize areas of intervention and to restructure inefficient or ineffective policies. Furthering this research will ultimately require enhanced multidisciplinary collaboration, as changes are likely to be needed not only in health policy, but in economic, social, and ecologic domains as well.

Achieving these research goals is challenging due to methodological limitations. For example, the measurement of key global-level constructs is complicated by the scale and the lack of precedent. Unstandardized measurements draw into question the comparability of results across studies. Additionally, the data collection methods and the data themselves vary in accuracy and completeness among different countries. Data quality depends on available resources and training of data collectors, as well as on logistical obstacles to data collection. All these factors are likely to vary by country or region of the world. Finally, the individuals and the institutions funding research influence what data are collected and how they are measured, which may affect the results and policy recommendations that follow. This is an issue of concern in studies of global contexts since the number of players is small and largely limited to international organizations with political agendas, such as the World Bank and the International Monetary Fund.

Analytic limitations also hinder the pursuit of epidemiologic research on pathways in a global context. One important issue is the potential for reciprocal interactions among the various levels of health determinants presented in our framework. For example, income growth may have a positive effect on health, but 
alternatively, the association seen between these variables may be due to reverse causation, in which good health may stimulate income growth. Although longitudinal studies can be designed to illuminate the directionality of this association, it is possible that the reality is bidirectional. In this case, current epidemiologic methods are unable to measure the relative importance of the directions of association. Another analytic challenge lies in the examination of multiple interactions between inter-level and intra-level components. Current analytic tools are capable of investigating interactions, but sample size and power become insufficient as multiple interactions are included in regression models.

Despite these challenges, epidemiologic research must strive to include the global context in analyses. We must avoid becoming "prisoners of the proximate," to borrow McMichael's (1999) terminology, and instead focus on identifying modifiable contextual factors likely to have a large impact on population health. Studying the global context will enable development of effective interventions and improved promotion and protection of population health.

\section{References}

Abarca, J., Casiccia, C., \& Zamorano, F. (2002). Increase in sunburns and photosensitivity disorders at the edge of the Antarctic ozone hole, Southern Chile, 1986-2000. Journal of the American Academy of Dermatology (JAAD), 46(2), 193-199.

Abu Morad, T. (2004). Palestinain refugee conditions associated with intestinal parasites and diarrhoea: Nuseirat refugee camp as a case study. Public Health, 188(2), 131-142.

Adler, N. E., \& Newman, K. (2002). Socioeconomic disparities in health: Pathways and policies. Health Affairs, 21(2), 60-76.

Adler, N. E., \& Ostrove, J. M. (1999). Socioeconomic status and health: What we know and what we don't. Annals of the New York Academy of Science, 896(1), 3-15.

Afrane, Y., Klinkenberg, E., Drechsel, P., Owusu-Daaku, K., Garms, R., \& Kruppa, T. (2004). Does irrigated urban agriculture influence the transmission of malaria in the city of Kumasi, Ghana? Acta Tropica, 89, 125-34.

Agnew, R. (1992). Foundation for a general strain theory of crime and delinquency. Criminology, 30, 47-87.

Ahmed, Q. A., Arabi, Y. M., \& Memish, Z. A. (2006). Health risks at the Hajj. The Lancet, 367(9515), 1008-1015.

Anderson, R., \& May, R. (1991). Infectious diseases of humans: Dynamics and control. New York: Oxford University Press.

Antunes, J. L. F., \& Waldman, E. A. (2001). The impact of AIDS, immigration and housing overcrowding on tuberculosis deaths in Sao Paulo, Brazil, 1994-1998. Social Science \& Medicine, 52(7), 1071-1080.

Arnett, J. (2002). The psychology of globalization. American Psychologist, 57(10), 774-783.

Atherholt, T., LeChevallier, M., Norton, W., \& Rosen, J. (1998). Effect of rainfall on giardia and cryptosporidium. Journal of the American Water Works Association, 90(9), $66-80$.

Ayala-Carcedo, F. J., \& Gonzalez-Barros, M. R. Y. (2005). Economic underdevelopment and sustainable development in the world: Conditioning factors, problems and opportunities. Environment, Development and Sustainability, 7(1), 95-115. 
Barker, D., Coggon, D., Osmond, C., \& Wickham, C. (1990). Poor housing in childhood and high rates of stomach cancer in England and Wales. British Journal of Cancer, 61(4), 575-578.

Baum, A., Garofalo, J. P., \& Yali, A. M. (1999). Socioeconomic status and chronic stress: Does stress account for SES effects on health? Annals of the New York Academy of Sciences, 896(1), 131-144.

Baum, F. (2001). Health, equity, justice and globalisation: Some lessons from the People's Health Assembly. Journal of Epidemiology and Community Health, 55, 613-616.

Bennett, S., \& Chanfreau, C. (2005). Approaches to rationing antiretroviral treatment: Ethical and equity implications. Bulletin of the World Health Organization, 83(7), 541-547.

Berkman, L. F., Glass, T., Brissette, L., \& Seeman, T. E. (2000). From social integration to health: Durkheim in the new millennium. Social Science \& Medicine, 51(6), 843-857.

Betrán, A., Wojdyla, D., Posner, S., \& Gülmezoglu, M. (2005). National estimates for maternal mortality: An analysis based on the WHO systematic review of maternal mortality and morbidity. BMC Public Health, 5, 131.

Bettcher, D., \& Lee, K. (2002). Globalisation and public health. Journal of Epidemiology and Community Health, 56(1), 8-17.

Bettcher, D., Yach, D., \& Guindon, G. (2000). Global trade and health: Key linkages and future challenges. Bulletin of the World Health Organization, 78(4), 521-534.

Bobak, M., Hertzman, C., Skodova, Z., \& Marmot, M. (1999). Socioeconomic status and cardiovascular risk factors in the Czech Republic. International Journal of Epidemiology, 28(1), 46-52.

Bouma, M., Dye, C., \& Van der Kaay, H. (1996). Falciparum malaria and climate change in the northwest frontier province of Pakistan. American Journal of Tropical Medicine and Hygiene, 55, 131-137.

Bowman, C. (2004). The pacific island nations: Towards shared representation. Managing the challenges of WTO participation. Geneva: World Trade Organization.

Breiman, R. F., Evans, M. R., Preiser, W., Maguire, J., Schnur, A., Li, A., Bekedam, H., \& Mackenzie, J.S. (2003). Role of China in the quest to define and control Severe Acute Respiratory Syndrome. Emerging Infectious Diseases, 9(9), 1037-041.

Brown, R. P. C., \& Connell, J. (2004). The migration of doctors and nurses from south Pacific island nations. Social Science \& Medicine, 58(11), 2193-2210.

Bruce, N., Perez-Padilla, R., \& Albalak, R. (2000). Indoor air pollution in developing countries: A major environmental and public health challenge. Bulletin of the World Health Organization, 78(9), 1078-1092.

Carneiro, F., Cifuentes, E., Tellez-Rojo, M., \& Romieu, I. (2002). The risk of ascaris lumbricoides infection in children as an environmental health indicator to guide preventive activities in Caparaó and Alto Caparaó, Brazil. Bulletin of the World Health Organization, 80(1), 40-46.

Centers for Disease Control and Prevention (CDC). (1996). Outbreaks of cyclospora cayetanensis infection - United States, 1996. Morbidity and Mortality Weekly Report, 14(25), 549-551.

Chanda, R. (2001). Trade in health services. Bulletin of the World Health Organization 80, $158-163$.

Cheadle, A., Psaty, B. M., Curry, S., Wagner, E., Diehr, P., Koepsell, T., \& Krystal, A. (1991). Community-level comparisons between the grocery store environment and individual dietary practices. Preventive Medicine, 20(2), 250-261. 
Chen, L., Evans, T., Anand, S., Boufford, J. I., Brown, H., Chowdhury, M., Caeto, M., Dare, L., Dussault, G., Elzinga, G., Fee, E., Habte, D., Hanvoravongchai, P., Jacobs, M., Kurowski, C., Mchael, S., Pablos-Mendez, A., Sewankambo, N., Solimano, G., Stilwell, B., de Waal, A., \& Wilbulpolprasert, S. (2004). Human resources for health: Overcoming the crisis. The Lancet, 364(9449), 1984-1990.

Cobb, S., \& Kasl, S. (1977). Termination: The consequences of job loss. Cincinnati, OH: Department of Health, Education and Welfare (NIOSH).

Coburn, D. (2000). Income inequality, social cohesion and the health status of populations: The role of neo-liberalism. Social Science \& Medicine, 51(1), 135-146.

Coburn, D. (2004). Beyond the income inequality hypothesis: Class, neo-liberalism, and health inequalities. Social Science \& Medicine, 58, 41-56.

Cohen, D. A., Farley, T. A., \& Mason, K. (2003). Why is poverty unhealthy? Social and physical mediators. Social Science \& Medicine, 57(9), 1631-1641.

Cohen, D. A., Mason, K., Bedimo, A., Scribner, R., Basolo, V., \& Farley, T. A. (2003). Neighborhood physical conditions and health. American Journal of Public Health, 93(3), 467-471.

Cohen, D., Spear, S., Scribner, R., Kissinger, P., Mason, K., \& Wildgen, J. (2000). "Broken windows" and the risk of gonorrhea. American Journal of Public Health, 90(2), 230-236.

Cohen, J. E. (2003). Human population: The next half century. Science, 302, 1172-1175.

Cohen, S., Tyrrell, D., \& Smith, A. (1991). Psychological stress and susceptibility to the common cold. New England Journal of Medicine, 325(9), 606-612.

Collins, T. (2003). Globalization, global health and access to health care. International Journal of Health Planning and Management, 18(2), 97-104.

Cornia, G. (2001). Globalization and health: Results and options. Bulletin of the World Health Organization, 79(9), 834-841.

Cosgrove, W., \& Rijsberman, F. (1998). Creating a vision for water, life, and the environment. Water Policy, 1(1), 115-122.

Cunningham-Rundles, S., McNeeley, D. F., \& Moon, A. (2005). Mechanisms of nutrient modulation of the immune response. Journal of Allergy and Clinical Immunology, 115(6), 1119-1128.

Curriero, F., Patz, J., Rose, J., \& Lele, S. (2001). The association between extreme precipitation and waterborn disease outbreaks in the United States, 1948-1994. American Journal of Public Health, 91(8), 1194-1200.

Davey Smith, G. (1996). Income inequality and mortality: Why are they related? British Medical Journal, 312(7037), 987-988.

de Onis, M., Monteiro, C., Akre, J., \& Glugston, G. (1993). The worldwide magnitude of protein-energy malnutrition: An overview from the WHO Global Database on Child Growth. Bulletin of the World Health Organization, 71(6), 703-712.

Diaz-Bonilla, E., Babinard, J., \& Pinstrup-Andersen, P. (2002). Opportunities and risks for the poor in developing countries. Working Paper No. 83. New Delhi: Indian Council for Research on International Economic Relations.

Diez Roux, A. (2003). Residential environments and cardiovascular risk. The Journal of Urban Health, 80(4), 569-589.

Dodgson, R., Lee, K., \& Drager, N. (2002). Global health governance: A conceptual review. Discussion paper no. 1, Center on Global Change and Health. London: London School of Hygiene and Tropical Medicine.

Dollar, D. (2001). Is globalization good for your health? Bulletin of the World Health Organization, 79(9), 827-833.

Dollar, D., \& Kray, A. (2002). Spreading the wealth. Foreign Affairs, 81(1), 120-133. 
Dooley, D., Fielding, J., \& Levi, L. (1996). Health and unemployment. Annual Review of Public Health, 17, 449-465.

Draper, C., Brubaker, G., Geser, A., Kilimali, A., \& Wernsdorfer, W. (1985). Serial studies on the evolution of chloroquine resistance in an area of east African receiving intermittent malaria chemosuppression. Bulletin of the World Health Organization, 63(1), $109-118$.

Elliott, M. (2000). The stress process in neighborhood context. Health Place, 6, 287-299.

Evans, J. A., May, J., Tominski, D., Eggelte, T., Marks, F., Abruquah, H. H., Meyer, C.G., Timmann, C., Agbenyega, T., \& Horstmann, R.D. (2005). Pre-treatment with chloroquine and parasite chloroquine resistance in Ghanaian children with severe malaria. The Quarterly Journal of Medicine, 98(11), 789-796.

Evans, J., Hyndman, S., Stewart-Brown, S., Smith, D., \& Petersen, S. (2000). An epidemiological study of the relative importance of damp housing in relation to adult health. Journal of Epidemiology and Community Health, 54(9), 677-686.

Feachem, R. (1984). Interventions for the control of diarrhoeal diseases among young children: Promotion of personal and domestic hygiene. Bulletin of the World Health Organization, 62, 467-476.

Fidler, D. P. (2004). Germs, governance, and global public health in the wake of SARS. The Journal of Clinical Investigation, 113(6), 799-804.

Filmer, D., \& Pritchett, L. (1999). The impact of public spending on health: Does money matter? Social Science \& Medicine, 49, 1309-1323.

Fischer, G., Shah, M., Tubiello, F., \& van Velhuizen, H. (2005). Socio-economic and climate change impacts on agriculture: An integrated assessment, 1990-2080. Philosophical Transactions of The Royal Society B: Biological Sciences, 360(1463), 2067-2083.

Franco, A., Alvarez-Dardet, C., \& Ruiz, M. T. (2004). Effect of democracy on health: Ecological study. British Medical Journal, 329(7480), 1421-1423.

Frankel, J., \& Romer, D. (1999). Does trade cause growth? American Economic Review, 89, 379-398.

Frenk, J. (2005). Globalization, health, and the role of telemedicine. Telemedicine and eHealth, 11(3), 291-295.

Frenk, J., Sepulveda, J., Gomez-Dantes, O., McGuinness, M. J., \& Knaul, F. (1997). The future of world health: The new world order and international health. British Medical Journal, 314(7091), 1404-1407.

Freudenberg, N., Fahs, M., Galea, S., \& Greenberg, A. (2006). The impact of New York City's 1975 fiscal crisis on the tuberculosis, HIV, and homicide syndemic. American Journal of Public Health, 96(3), 424-434.

Frumkin, J. (2002). Urban sprawl and public health. Public Health Reports, 117(3), 201-217.

Galea, S., \& Ahern, J. (2005). Distribution of education and population health: An ecological analysis of New York City neighborhoods. American Journal of Public Health, 95(12), 2198-2205.

Galea, S., Freudenberg, N., \& Vlahov, D. (2005). Cities and population health. Social Science \& Medicine, 60(5), 1017-1033.

Galea, S., Rudenstine, S., \& Vlahov, D. (2005). Drug use, misuse and the urban environment. Drug and Alcohol Review, 24, 127-136.

Galea, S., \& Vlahov, D. (2005). Urban health: Evidence, challenges and directions. Annual Review of Public Health, 26, 341-165.

Gallup, J., Sachs, J., \& Mellinger, A. (1999). Geography and economic development. International Regional Science Review, 22(2), 179-232. 
Gemmell, I. (2001). Indoor heating, house conditions, and health. Annual Review of Public Health, 55(12), 928-929.

Gerdtham, U.-G., \& Johannesson, J. (2005). Business cycles and mortality: Results from Swedish microdata. Social Science \& Medicine, 60(1), 205-218.

Global Health Watch (2005). Global health watch 2005-2006: An alternative world health report. London: Zed Books.

Gopalan, C. (2001). Achieving household nutrition security in societies in transition: An overview. Asia Pacific Journal of Clinical Nutrition, 10(Supplement), S4-S12.

Gracey, M. (2002). Child health in an urbanizing world. Acta Paediatrica, 91, 1-8.

Gupta, A. G., Moyer, C. A., \& Stern, D. T. (2005). The economic impact of quarantine: SARS in Toronto as a case study. Journal of Infection, 50(5), 386-393.

Habenicht, H. (1994). The international programme on the elimination of child labour: An international response to child labour. International Child Health, 2, 19-25.

Haddad, S., \& Fournier, P. (1995). Quality, cost and utilization of health services in developing countries. A longitudinal study in Zaire. Social Science \& Medicine, 40(6), $743-753$.

Hadley, J. (2003). Sicker and poorer-the consequences of being uninsured: A review of the research on the relationship between health insurance, medical care use, health, work, and income. Medical Care Research and Review, 60(supplement 2), 3S-75.

Hamilton, V., Broman, C., Hoffman, W., \& Renner, D. (1990). Hard times and vulnerable people: Initial effects of plant closing on autoworkers' mental health. Journal of Health and Social Behavior, 31(2), 123-140.

Handy, S., Boarnet, M., Ewing, R., \& Killingsworth, R. (2002). How the built environment affects physical activity: Views from urban planning. American Journal of Preventive Medicine, 23(2), 64-73.

Hawamdeh, H., \& Spencer, N. (2003). The effects of work on the growth of Jordanian boys. Child: Care, Health and Development, 29 (3), 167-172.

Hawkes, C. (2006). Uneven dietary development: Linking the policies and processes of globalization with the nutrition transition, obesity and diet-related chronic diseases. Globalization and Health, 2 (1), 4.

Hawryluck, L., Gold, W. L., Robinson, S., Pogorski, S., Galea, S., \& Styra, R. (2002). SARS control and psychological effects of quarantine, Toronto, Canada. Emerging Infectious Diseases, 10(7), 1206-1212.

Hemingway, H., Shipley, M., Macfarlane, P., \& Marmot, M. (2000). Impact of socioeconomic status on coronary mortality in people with symptoms, electrocardiographic abnormalities, both or neither: The original Whitehall study 25 year follow up. Journal of Epidemiology and Community Health, 54(7), 510-516.

Heymann, D. (2004). The international response to the outbreak of SARS in 2003. Philosophical Transactions of the Royal Society B: Biological Sciences, 359(1447), $1127-1129$.

Hippert, C. (2002). Multinational corporations, the politics of the world economy, and their effects on women's health in the developing world: A review. Health Care for Women International, 23, 861-869.

Hochberg, M. (2004). A theory of modern cultural shifts and meltdowns. Proceedings of the Royal Society of London, Section B: Biological Sciences, 271 (Supplement), S313-S316.

Holden, C. (1999). Stalking a killer in Russia's prisons. Science, 286(5445), 1670.

Holton, R. (2000). Globalization's cultural consequences. Annals of the American Academy of Political and Social Science, 570, 140-152. 
Huynen, M., Martens, P., \& Hilderink, H. (2005). The health impacts of globalisation: A conceptual framework. Globalization and Health, 1(1), 14.

Institute of Medicine. (2002). Care without coverage: Too little, too late. Washington, DC: National Academy Press.

International Program on the Elimination of Child Labor. (2002). Every child counts: New global estimates on child labour. Geneva: International Labour Office.

Internet World Stats (2006). Internet usage statistics - The big picture. (2006); http://www.internetworldstats.com/stats.htm

Jones, M. B., \& Jones, D. R. (1995). Preferred pathways of behavioral contagion. Journal of Psychiatric Research, 29(3), 193-209.

Jones, R. (1987). Ozone depletion and cancer risk. The Lancet, 2, 443-446.

Kaplan, G. (1999). What is the role of the social environment in understanding inequalities in health? Annals of the New York Academy of Sciences, 896, 116-119.

Kaplan, G. A., Pamuk, E. R., Lynch, J. W., Cohen, R. D., \& Balfour, J. L. (1996). Inequality in income and mortality in the United States: Analysis of mortality and potential pathways. British Medical Journal, 312(7037), 999-1003.

Kawachi, I., \& Berkman, L. (2001). Social ties and mental health. Journal of Urban Health, 78 (3), 458-67.

Kawachi, I., Kennedy, B., Lochner, K., \& Prothrow-Stith, D. (1997). Social captial, income inequality, and mortality. American Journal of Public Health, 87, 1491-1498.

Kawachi, I., Kennedy, B. P., \& Wilkinson, R. G. (1999). Crime: Social disorganization and relative deprivation. Social Science \& Medicine, 48(6), 719-731.

Keating, J., MacIntyre, K., Mbogo, C., Githeko, A., Regens, J. L., Swalm, C., Ndenga, B., Steinberg, L.J., Kibe, L., Githure, J.I., \& Beier, J.C. (2003). A geographic sampling strategy for studying relationships between human activity and malaria vectors in urban Africa. American Journal of Tropical Medicine and Hygiene, 68(3), 357-365.

Kennedy, B. P., Kawachi, I., Prothrow-Stith, D., Lochner, K., \& Gupta, V. (1998). Social capital, income inequality, and firearm violent crime. Social Science \& Medicine, 47(1), $7-17$.

Kinnon, C. (1998). World trade: Bringing health into the picture. World Health Forum, 19, 397-406.

Klevens, R. M., \& Luman, E. T. (2001). U.S. children living in and near poverty: Risk of vaccine-preventable diseases. American Journal of Preventive Medicine, 20(4, Supplement 1), 41-46.

Konradsen, F., Amerasinghe, P., Van Der Hoek, W., Amerasinghe, F., Perera, D., \& Piyaratne, M. (2003). Strong association between house characteristics and malaria vectors in Sri Lanka. American Journal of Tropical Medicine and Hygiene, 68(2), 177-181.

Korte, S. M., Koolhaas, J. M., Wingfield, J. C., \& McEwen, B. S. (2005). The darwinian concept of stress: Benefits of allostasis and costs of allostatic load and the trade-offs in health and disease. Neuroscience \& Biobehavioral Reviews, 9(1), 3-38.

Kosek, M., Bern, C., \& Guerrant, R. (2003). The global burden of diarrhoeal disease, as estimated from studies published between 1992 and 2000. Bulletin of the World Health Organization, 81, 197-204.

Krieger, J., \& Higgins, D. (2002). Housing and health: Time again for public health action. American Journal of Public Health, 92(5), 758-768.

Labonte, R., Muhajarine, N., Abonyi, S., Woodard, G., Jeffery, B., Maslany, G., Mc Cubbin, M., \& Williams, S.A., (2002). An integrated exploration into the social and environmental determinants of health: The Saskatchewan Population Health and Evaluation Research Unit (SPHERU). Chronic Diseases in Canada, 23(2), 71-76. 
LaScala, E. A., Gerber, D., \& Gruenewald, P. J. (2000). Demographic and environmental correlates of pedestrian injury collisions: A spatial analysis. Accident Analysis \& Prevention, 32(5), 651-658.

Latkin, C., \& Curry, A. (2003). Stressful neighborhoods and depression: A prospective study of the impact of neighborhood disorder. Journal of Health and Social Behavior, 44(1), 34-44.

LaVeist, T. A., \& Wallace, J. M., Jr. (2000). Health risk and inequitable distribution of liquor stores in African American neighborhood. Social Science \& Medicine, 51(4), 613-617.

Lee, K. (2000). Globalization and health policy: A conceptual framework and research and policy agenda. In A. Bambas, J. A. Drayton, H. A. Drayton, \& A. Valdez (Eds.), Health and human development in the new global economy: The contributions and perspectives of civil society in the Americas. Washington, DC: Pan American Health Organization.

Lee, T., Jordan, N. N., Sanchez, J. L., \& Gaydos, J. C. (2005). Selected nonvaccine interventions to prevent infectious acute respiratory disease. American Journal of Preventive Medicine, 28(3), 305-316.

Lepore, S., Evans, G., \& Palsane, M. (1991). Social hassles and psychological health in the context of chronic crowding. Journal of Health and Social Behavior, 32(4), $357-367$.

Lindsay, S. W., Emerson, P. M., \& Charlwood, J. D. (2002). Reducing malaria by mosquito-proofing houses. Trends in Parasitology, 18(11), 510-514.

Link, B. G., \& Phelan, J. (1995). Social conditions as fundamental causes of disease. Journal of Health and Social Behavior, 92(5), 730-732.

Liu, Y. (2004). China's public health-care system: Facing the challenges. Bulletin of the World Health Organization, 82(7), 532-538.

Loevinsohn, M. E. (1994). Climatic warming and increased malaria incidence in Rwanda. The Lancet, 343(8899), 714-718.

Loewenson, R. (1998). Assessment of the health impact of occupational risk in Africa: Current situation and methodological issues. Epidemiology, 10(5), 632-639.

Loewenson, R. (2001). Globalization and occupational health: A perspective from southern Africa. Bulletin of the World Health Organization, 79(9), 863-868.

Lynch, J., Kaplan, G. A., Salonen, R., Cohen, R. D., \& Salonen, J. T. (1995). Socioeconomic status and carotid atherosclerosis. Circulation, 92(7), 1786-1792.

Lynch, J., Smith, G., Harper, S., Hillemeier, M., Ross, N., Kaplan, G. A., \& Wolfson, M. (2004). Is income inequality a determinant of population health? Part 1. A systematic review. The Milbank Quarterly, 82(1), 5-99.

Lynch, J. W., Smith, G. D., Kaplan, G. A., \& House, J. S. (2000). Income inequality and mortality: Importance to health of individual income, psychosocial environment, or material conditions. British Medical Journal, 320(7243), 1200-1204.

Marmot, M. (2002). The influence of income on health: Views of an epidemiologist. Health Affairs, 21 (2), 31-46.

Marmot, M., \& Wilkinson, R. G. (2001). Psychosocial and material pathways in the relation between income and health: A response to Lynch et al. British Medical Journal, 322(7296), 1233-1236.

Mayberry, R. M., Mili, F., \& Ofili, E. (2000). Racial and ethnic differences in access to medical care. Medical Care Research and Review, 57(supplement 1), 108-145.

McEwen, B. S. (2004). Protection and damage from acute and chronic stress: Allostasis and allostatic overload and relevance to the pathophysiology of psychiatric disorders. Annals of the New York Academy of Sciences, 1032 (1), 1-7. 
McEwen, B. S., \& Seeman, T. (1999). Protective and damaging effects of mediators of stress: Elaborating and testing the concepts of allostasis and allostatic load. Annals of the New York Academy of Sciences, 896(1), 30-47.

McLeod, J., \& Kessler, R. (1990). Socioeconomic status differences in vulnerability to undesirable life events. Journal of Health and Social Behavior, 31(2), 162-172.

McMihael, A.J., (1999). Prisoners of the proximate: loosening the constraints on epidermiology in an age of change. American Journal of Epidemiology, 149(10), 887-897.

McMichael, A. (2000). The urban environment and health in a world of increasing globalization: Issues for developing countries. Bulletin of the World Health Organization, 78(9), 1117-1126.

McMichael, A., \& Beaglehole, R. (2000). The changing global context of public health. The Lancet, 356(9228), 495-499.

McMichael, A. J., Bolin, B., Costanza, R., Daily, G. C., Folke, C., Lindahl-Kiessling, K., Lingren, E., \& Niklasson, B. (1999). Globalization and the sustainability of human health: An ecological perspective. BioScience, 49(3), 205-210.

Meerman, L., Ord, R., Bousema, J. T., van Niekerk, M., Osman, E., Hallett, R., Pinder, M., Walraven, G., \& Sutherland, C.J. (2005). Carriage of chloroquine-resistant parasites and delay of effective treatment increase the risk of severe malaria in Gambian children. Journal Infectious Diseases, 192(9), 1651-1657.

Mehrotra, S. (2006). Governance and basic social services: Ensuring accountability in service delivery through deep democratic decentralization. Journal of International Development, 18, 263-283.

Menon-Johansson, A. S. (2005). Good governance and good health: The role of societal structures in the human immunodeficiency virus pandemic. BMC International Health and Human Rights, 5(1), 4.

Moore, M., Gould, P., \& Keary, B. S. (2002). Global urbanization and impact on health. International Journal of Hygiene and Environmental Health, 206, 269-278.

Moore, S., Teixeira, A. C., \& Shiell, A. (2006). The health of nations in a global context: Trade, global stratification, and infant mortality rates. Social Science \& Medicine, 63(1), $165-178$.

Muntaner, C., \& Lynch, J. (1999). Income inequality, social cohesion, and class relations: A critique of Wilkinson's neo-Durkheimian research program. International Journal of Health Services, 29(1), 59-81.

Myaux, J., Ali, M., Felsenstein, A., Chakraborty, J., \& de Francisco, A. (1997). Spatial distribution of watery diarrhoea in children: Identification of risk areas in a rural community in Bangladesh. Health \& Place, 3(3), 181-186.

Nations, M. K., \& Monte, C. M. J. (1996). I'm not dog, no: Cries of resistance against cholera control campaigns. Social Science \& Medicine, 43(6), 1007-1024.

Navarro, V., \& Shi, L. (2001). The political context of social inequalities and health. Social Science \& Medicine, 52(3), 481-491.

Netterstrom, B., \& Hansen, A. (2000). Outsourcing and stress: Physiological effects on bus drivers. Stress Medicine, 16, 149-60.

Newman, O. (1986). Defensible space: Crime prevention through urban design. New York: MacMillan.

Ostry, A. S., \& Spiegel, J. M. (2004). Labor markets and employment insecurity: Impacts of globalization on service and healthcare-sector workforces. International Journal of Occupational and Environmental Health, 10(4), 368-374.

Pascual, M., Rodo, X., Ellner, S. P., Colwell, R., \& Bouma, M. J. (2000). Cholera dynamics and El Nino-Southern Oscillation. Science, 289(5485), 1766-1769. 
Phillips, D., \& Carstensen, L. (1986). Clustering of teenage suicides after television news stories about suicide. New England Journal of Medicine, 315(11), 385-389.

Pick, W. M., \& Obermeyer, C. M. (1996). Urbanisation, household composition and the reproductive health of women in a South African city. Social Science \& Medicine, 43(10), 1431-1441.

Poon, L., Guan, Y., Nicholls, J., Yuen, K., \& Peiris, J. (2004). The aetiology, origins, and diagnosis of Severe Acute Respiratory Syndrome. The Lancet Infectious Diseases, 4(11), 663-671.

Pritchett, L., \& Summers, L. (1996). Wealthier is healthier. Journal of Human Resources, 31, 841-868.

Quinlan, M., Mayhew, C., \& Bohle, P. (2001). The global expansion of precarious employment, work disorganization, and consequences for occupational health: A review of recent research. International Journal of Health Services, 31(2), 335-414.

Quinn, T. C. (1994). Population migration and the spread of types 1 and 2 human immunodeficiency viruses. Proceedings of the National Academy of Sciences, 91, 2407-2414.

Ravillion, M. (2001). Growth, inequality and poverty: Looking beyond averages. UNU/WIDER Conference on Growth and Poverty, Helsinki.

Root, G. (1997). Population density and spatial differentials in child mortality in Zimbabwe. Social Science \& Medicine, 44(3), 413-421.

Ross, C., \& Mirowsky, J. (2001). Neighborhood disadvantage, disorder, and health. Journal of Health and Social Behavior, 42(3), 258-276.

Ross, C., \& Wu, C. (1995). The links between education and health. American Sociological Review, 60(5), 715-745.

Rush, D. (2000). Nutrition and maternal mortality in the developing world. American Journal of Clinical Nutrition, 72(1), 212S-240S.

Sampson, R., \& Groves, W. (1989). Community structure and crime: Testing socialdisorganization theory. The American Journal of Sociology, 94(4), 774-802.

Sampson, R. J., Raudenbush, S. W., \& Earls, F. (1997). Neighborhoods and violent crime: A multilevel study of collective efficacy. Science, 277(5328), 918-924.

Satterthwaite, D. (2000). Will most people live in cities? British Medical Journal, 321, $1143-1145$.

Schilling, J., \& Linton, L. (2005). The public health roots of zoning: In search of active living's legal genealogy. American Journal of Preventive Medicine, 28 (2 Supplement 2), 96-104.

Segall, M. (2000). From cooperation to competition in national health systems - and back? Impact on professional ethics and quality of care. The International Journal of Health Planning and Management, 15(1), 61-79.

Semenza, J. C., Rubin, C. H., Falter, K. H., Selanikio, J. D., Flanders, W. D., Howe, H. L., \& Wilhelm, J. (1996). Heat-related deaths during the July 1995 heat wave in Chicago. New England Journal of Medicine, 335(2), 84-90.

Sen, A. (1997). Inequality, unemployment and contemporary Europe. International Labor Review, 136(2), 155-172.

Shaw, C., \& McKay, H. (1942). Juvenile delinquency and urban areas. Chicago: University of Chicago Press.

Shetty, P. (2006). Achieving the goal of halving global hunger by 2015. The Summer Meeting of the Nutrition Society, Norwich, Proceedings of the Nutrition Society.

Skrabski, A., Kopp, M., \& Kawachi, I. (2004). Social capital and collective efficacy in Hungary: Cross sectional associations with middle aged female and male mortality rates. Journal of Epidemiology and Community Health, 58(4), 340-345. 
Smith, A., Lingas, E., \& Rahman, M. (2000). Contamination of drinking-water by arsenic in Bangladesh: A public health emergency. Bulletin of the World Health Organization, 78(9), 1093-1103.

Smolinski, M. S., Hamburg, M. A., \& Lederberg, J. (Eds.). (2003). Microbial threats to health: Emergence, detection and response. Washington, D.C., Institute of Medicine.

Spiegel, J. M., Labonte, R., \& Ostry, A. S. (2004). Understanding globalization as a determinant of health determinants: A critical perspective. International Journal of Occupational Medicine and Environmental Health, 10(4), 360-367.

Stevenson, L., Latham, M., \& Ottesen, E. (2000). Global malunutrition. Parasitology, 121(7), S5-S22.

Stloukal, L. (2001). Rural population ageing in poorer countries: Possible implications for rural development. SDdimensions. (2001); http://www.fao.org/sd/2001/pe0501a_en.htm

Subramanian, S., Belli, P., \& Kawachi, I. (2002). The macroeconomic determinants of health. Annual Review of Public Health, 23, 287-302.

Subramanian, S., Kim, D., \& Kawachi, I. (2002). Social trust and self-rated health in US communities: A multilevel analysis. Journal of Urban Health, 79(4 Supplement 1), S21-S34.

Subramanian, S. V., \& Kawachi, I. (2004). Income inequality and health: What have we learned so far? Epidemiologic Reviews, 26(1), 78-91.

Sundquist, K., Theobald, H., Yang, M., Li, X., Johansson, S., \& Sundquist, J. (2006). Neighborhood violent crime and unemployment increase the risk of coronary heart disease: A multilevel study in an urban setting. Social Science \& Medicine, 62(8), 2061-2071.

Szreter, S. (1997). Economic growth, disruption, deprivation and death: On the importance of the politics of public health for development. Population and Development Review, $23,702-703$.

Takkouche, B., Regueira, C., \& Gestal-Otero, J. (2001). A cohort study of stress and the common cold. Epidemiology, 12(3), 345-349.

The Eurowinter Group. (1997). Cold exposure and winter mortality from ischaemic heart disease, cerebrovascular disease, respiratory disease, and all causes in warm and cold regions of Europe. Lancet, 349(9062), 1341-1346.

United Nations. (2002). International migration report 2002. New York: United Nations.

United Nations. (2005). UN Millennium Project 2005. Health, dignity, and development: What will it take? New York: United Nations.

United Nations Department of Economic and Social Affairs. (2003). World urbanization prospects: The 2003 Revision. New York: United Nations.

United Nations Development Programme. (2001). Human development report. New York: Oxford University Press.

United Nations High Commissioner for Refugees. (2004). Basic facts. United Nations High Commissioner for Refugees. New York: United Nations.

VanDerslice, J., Popkin, B., \& Briscoe, J. (1994). Drinking-water quality, sanitation, and breastfeeding: their interactive effects on infant health. Bulletin of the World Health Organization, 72, 589-601.

Vitousek, P., Mooney, H., Lubchenco, J., \& Melillo, J. (1997). Human domination of the earth's ecosystems. Science, 277, 494-499.

Wade, R. (2004). Is globalization reducing poverty and inequality? World Development, 32(4), 567-589.

Wagstaff, A., Bustreo, F., Bryce, J., \& Claeson, M. (2004). Child health: Reaching the poor. American Journal of Public Health, 94(5), 726-736. 
Wakefield, S. E. L., \& Poland, B. (2005). Family, friend or foe? Critical reflections on the relevance and role of social capital in health promotion and community development. Social Science \& Medicine, 60(12), 2819-2832.

Wallace, D., \& Wallace, R. (1998). Scales of geography, time, and population: The study of violence as a public health problem. American Journal of Public Health, 88(12), $1853-1858$.

Webster, R. G. (2004). Wet markets - a continuing source of severe acute respiratory syndrome and influenza? The Lancet, 363(9404), 234-236.

Weich, S., Blanchard, M., Prince, M., Burton, E., Erens, B., \& Sproston, K. (2002). Mental health and the built environment: Cross-sectional survey of individual and contextual risk factors for depression. British Journal of Psychiatry, 180(5), 428-433.

Weinreb, L., Wehler, C., Perloff, J., Scott, R., Hosmer, D., Sagor, L., \& Gundersen, C. (2002). Hunger: Its impact on children's health and mental health. Pediatrics, 110(4), e41.

Weisbrot, M., Baker, D., Kraev, E., \& Chen, J. (2002). The scorecard on globalization 1980-2000: Its consequences for economic and social well-being. International Journal of Health Services, 32(2), 229-253.

Wellington, M., Ndowa, F., \& Mbengeranwa, L. (1997). Risk factors for sexually transmitted disease in Harare: A case-control study. Sexually Transmitted Diseases, 24(9), $528-532$.

Widdus, R. (2005). Public-private partnerships: An overview. Transactions of the Royal Society of Tropical Medicine and Hygiene, 99(Supplement 1), 1-8.

Wilkinson, R. G., \& Pickett, K. E. (2006). Income inequality and population health: A review and explanation of the evidence. Social Science \& Medicine, 62(7), 1768-1784.

Williams, L., Labonte, R., \& O'Brien, M. (2003). Empowering social action through narratives of identity and culture. Health Promotion International, 18(1), 33-40.

Williams, R. (1987). Meningitis and unpaved roads. Social Science \& Medicine, 24(2), $109-115$.

Williamson, J. B., \& Boehmer, U. (1997). Female life expectancy, gender stratification, health status, and level of economic development: A cross-national study of less developed countries. Social Science \& Medicine, 45(2), 305-317.

Wilson, M.E. (2003). The traveller and emerging infections: sentinel courier, transmitter. Journal of Applied Microbiology, 94(1), 1S-11S

Woodward, D., Drager, N., Beaglehole, R., \& Lipson, D. (2001). Globalization and health: A framework for analysis and action. Bulletin of the World Health Organization, 79(9), 875-881.

World Bank. (2006). World Development Indicators 2006. Washington, DC: The World Bank.

World Health Organization. (2003). Consensus document on the epidemiology of Severe Acute Respiratory Syndrome (SARS). Geneva: World Health Organization.

World Health Organization. (2004). Water, sanitation and hygiene links to health: Facts and figures. Geneva: World Health Organization.

World Health Organization. (2006). World health report 2006: Working together for health. Geneva: World Health Organization.

World Trade Organization. (2000a). World merchandise trade by selected region and economy, 1980-99. Geneva: World Trade Organization.

World Trade Organization. (2000b). World trade in commercial services by selected region and economy, 1980-99. Geneva: World Trade Organization.

World Trade Organization. (2005). World tourism barometer. Geneva: World Trade Organization. 
Yach, D., \& Bettcher, D. (2000). Globalisation of tobacco industry influence and new global responses. Tobacco Control, 9(2), 206-216.

Yé, Y., Hoshen, M., Louis, V., Séraphin, S., Traoré, I., \& Sauerborn, R. (2006). Housing conditions and Plasmodium falciparum infection: Protective effect of iron-sheet roofed houses. Malaria Journal, 5, 8 .

Zenk, S. N., Schulz, A. J., Israel, B. A., James, S. A., Bao, S., \& Wilson, M. L. (2005). Neighborhood racial composition, neighborhood poverty, and the spatial accessibility of supermarkets in metropolitan Detroit. American Journal of Public Health, 95(4), 660-667.

Zenk, S. N., Schulz, A. J., Israel, B. A., James, S. A., Bao, S., \& Wilson, M. L. (2006). Fruit and vegetable access differs by community racial composition and socioeconomic position in Detroit, Michigan. Ethnicity \& Disease, 16(1), 275-280.

Zhou, G., Minakawa, N., Githeko, A. K., \& Yan, G. (2004). Association between climate variability and malaria epidemics in the East African highlands. Proceedings of the National Academy of Sciences of the United States of America, 101(8), 2375-2380. 